•研究报告・

\title{
辽东山区次生林乔木幼苗组成及其年际动态
}

\author{
蔡军奇 ${ }^{1}$ 刘大鹏 ${ }^{2} \quad$ 张淑媛 $^{1} \quad$ 宗 $^{1}$ 刘 $^{\text {佳 }}{ }^{1} \quad$ 白雪娇 $1,3^{*}$ \\ 1 (沈阳农业大学林学院, 沈阳 110866) \\ 2 (本溪满族自治县兰河峪林场, 辽宁本溪 117103) \\ 3 (中国科学院清原森林生态系统观测研究站, 沈阳 110016)
}

\begin{abstract}
摘要: 为了解辽东山区次生林乔木幼苗组成及其年际动态, 本文以 4 ha动态监测样地为平台, 对样地内 1,600 个 $5 \mathrm{~m} \times 5 \mathrm{~m}$ 样方进行监测。依据2014-2016年连续3年的调查, 对样地内乔木幼苗的组成、高度分布、新增和死亡年 际动态、空间分布格局等进行分析。结果表明: (1)调查期间共记录到22种乔木幼苗, 3年间幼苗组成没有发生变化, 但各个样方间出现极大差异, 并且幼苗优势树种组成与样地内优势树种成分保持着一定的相似性。(2)幼苗数量在 不同树种和年际间表现出较大的差异: 花曲柳(Fraxinus rhynchophylla)、色木械(Acer mono)、胡桃梑(Juglans mandshurica) 在3年间幼苗数量最多, 占幼苗总数的 $75.6 \%$; 花曲柳和胡桃楸幼苗数量表现出较明显的年际波动, 其他树种波动较小, 不同树种的幼苗密度差异很大。(3)幼苗新增和死亡存在明显的种间和年际差异: 2014-2015年 间幼苗的新增数量(3,888) 明显高于2015-2016年间(1,710), 同时 2014-2015年间幼苗死亡率(23.7\%)也明显高于 2015-2016年间(12.7\%)。对2015-2016年间新增幼苗和已有幼苗的死亡情况进行比较可以发现, 新增幼苗总体死亡 率(18.8\%)明显高于已有幼苗(8.1\%)。(4)对比幼苗和大树的空间分布可以发现, 样地内优势幼苗都表现出集群分布 的特征。在空间分布上，幼苗与母树保持一定的相似性。
\end{abstract}

关键词：森林更新；年际动态；空间分布；辽东山区; 次生林

\section{Composition and interannual dynamics of tree seedlings in a secondary forest in montane region of eastern Liaoning Province, China}

\author{
Junqi Cai ${ }^{1}$, Dapeng Liu $^{2}$, Shuyuan Zhang ${ }^{1}$, Guo Zong ${ }^{1}$, Jia Liu ${ }^{1}$, Xuejiao Bai ${ }^{1,3 *}$ \\ 1 College of Forestry, Shenyang Agricultural University, Shenyang 110866 \\ 2 Benxi Manzu Autonomous County Lanhe Valley Forest Farm, Benxi, Liaoning 117103 \\ 3 Qingyuan Forest Ecosystem Observation Station, Chinese Ecosystem Research Network, Chinese Academy of Sciences, \\ Shenyang 110016
}

\begin{abstract}
To explore the composition and interannual dynamics of tree seedlings in the montane region of eastern Liaoning Province in China, we established 1,600 seedling quadrats of size $5 \mathrm{~m} \times 5 \mathrm{~m}\left(25 \mathrm{~m}^{2}\right)$ within a 4-ha plot to monitor forest dynamics. We analyzed species composition, height-class structure, interannual dynamics and spatial distribution of tree seedlings from three censuses (2014 to 2016). We recorded a total of 22 species of tree seedlings during the survey period. The species composition of tree seedlings did not vary significantly among years, but varied greatly among quadrats. Species that dominated as seedlings largely reflected the dominant species among adults. Tree seedling numbers varied significantly among different tree species across years, with Fraxinus rhynchophylla, Acer mono and Juglans mandshurica accounting for $75.6 \%$ of the total seedlings in the three censuses. The abundances of F. rhynchophylla and J. mandshurica seedlings varied greatly among three years, while the other species varied little. Similarly, seedling density also varied greatly among different species. We also found interspecific and interannual variation in new seedling recruits and those that died. Recruit abundance during 2014-2015 (3,888) was higher than 2015-2016 (1,710), and the seedling mortality rate was also higher in 2014-2015 (23.7\%) than 2015-2016
\end{abstract}

收稿日期: 2018-05-04; 接受日期: 2018-08-18

基金项目: 国家重点研发计划项目子课题(2017YFC050410501)、辽宁省农业领域青年科技创新人才培养计划项目(2015047)和国家自然科学基金 (31300378)

* 通讯作者 Author for correspondence. E-mail: bxjiao1984@163.com 
(12.7\%). The mortality rate of recruited seedlings (18.8\%) was higher than that of existing seedlings (8.1\%) during 2015-2016. Finally, we found that the dominant seedlings showed spatially clustered distributions and the spatial pattern of seedling distributions was consistent with that of adults of the species.

Key words: forest regeneration; interannual dynamics; spatial distribution; montane region of eastern Liaoning Province; secondary forest

森林天然更新是生态系统自我恢复和演替的 过程, 是森林生态系统动态研究的主要内容之一 (徐振邦等, 2001)。在森林群落更新过程中, 木本植 物种群不断地发展和演替, 对未来森林群落的结构 与组成具有深远的影响(Harms et al, 2000)。林下幼 苗是森林生态系统的重要组成部分(李洁琼等, 2016), 是潜在的森林更新库(Swamy et al, 2011), 在 森林更新和生态恢复过程中发挥着重要的作用 (Fyllas et al, 2010; 苏嫄等, 2014)。在相关研究中, 幼苗阶段始终被认为是植物生活史中个体数量变 化最大、生长最脆弱、对环境变化最敏感的时期 (Clark \& Clark, 1984; Shimono \& Kudo, 2003; 彭闪 江等, 2004; Wright et al, 2005), 同时, 幼苗状况也 能反映出森林的演替能力(苏嫄等, 2014)。因此, 深 入理解林下幼苗的组成、结构、存活和生长规律等 是生物多样性保护和森林生态系统经营管理的基 础(张健等, 2009), 有助于理解和预测森林群落组成 和结构的动态变化。

在森林群落中, 不论是群落水平, 还是种群水 平, 幼苗动态在时间和空间上都存在很大的变异 (Connell \& Green, 2000; Norden et al, 2007), 尤其是 新增幼苗(Metz et al, 2008)。由于幼苗动态在维持林 下幼苗多样性和促进物种共存方面起到重要的作 用(Metz et al, 2010), 相关的研究受到众多学者的关 注。近年来, 我国学者参照美国热带森林科学研究 中心(Centre for Tropical Forest Science, CTFS)样地 建设标准和操作规范, 已在很多地区建立了大型森 林固定动态监测样地, 如长白山、古田山、鼎湖山、 西双版纳、宝天曼等样地, 这些固定样地的建立极 大地促进了林下幼苗的研究。国内在幼苗组成与动 态方面的研究大多基于固定样地内均匀设置的小 样方, 例如李晓亮等(2009)、张健等(2009)和间琰等 (2016)的研究。然而, 采用样地普查的方式对幼苗进 行的研究较少, 仅见于席朝骏等(2017)的研究中。

辽宁东部山区次生林是由原生的地带性顶极 群落阔叶红松(Pinus koraiensis)林破坏后逐渐形成
的(胡理乐等, 2005), 现有次生林面积 $1.20 \times 10^{7} \mathrm{ha}$, 占该区森林总面积的 $84 \%$, 肩负着维护区域内的生 态平衡、环境保护、空气净化、水土保持、水源涵 养、气候调节、农业生产及振兴辽宁老工业基地的 重要任务, 是辽东山区森林资源的重要组成部分 (孔祥文等, 2002)。本文以辽东山区次生林4 ha动态 监测样地为平台, 基于2014-2016年连续3年的林下 幼苗监测数据, 对林下乔木幼苗的组成及其年际动 态进行分析, 旨在: (1)分析林下乔木幼苗的树种组 成和数量特征及其在年际间的动态变化规律; (2)分 析乔木幼苗和同种大树在空间分布上的异同。

\section{材料与方法}

\section{1 研究地概况}

研究区位于辽宁省东部山区清原满族自治县 次生林内 $\left(41^{\circ} 51.102^{\prime} \mathrm{N}, 124^{\circ} 54.543^{\prime} \mathrm{E}\right)$, 属于长白山 山脉的余脉, 海拔为252-1,116 m, 主要以山地为主, 土壤为典型的棕色土壤。气候属于暖温带大陆性气候, 夏季炎热多雨, 冬季寒冷漫长。全年无霜期120-139 d, 年平均日照 $2,433 \mathrm{~h}$ 。年平均气温3.9-5.4 ${ }^{\circ} \mathrm{C}$, 降雨集 中在6-8月, 年降雨量806.5 mm (李秀芬等, 2004)。 研究区植被属长白植物区系, 主要有红松、蒙古栎 (Quercus mongolica)、色木槭(Acer mono)、紫椴(Tilia amurensis)、水曲柳(Fraxinus mandshurica)和胡桃楸 (Juglans mandshurica) 等珍贵树种。

\section{2 研究方法}

\subsection{1 样地设置与植被调查}

2013年8月, 参照CTFS样地建设标准和操作规 范(Condit, 1995)在清原站附近的实验林内设置一块 4 ha次生林固定监测样地, 样地规格为 $200 \mathrm{~m} \times 200 \mathrm{~m}$, 用全站仪将整个样地划分成 100 个 $20 \mathrm{~m} \times 20 \mathrm{~m}$ 的样 方, 调查样方内所有胸径 $(\mathrm{DBH}) \geq 1 \mathrm{~cm}$ 的木本植物, 记录植株的种类、胸径及坐标等, 并挂牌标记, 以 便进行永久监测。样地海拔为685.5-780.5 m, 平均 海拔728.2 m, 最大高差95.0 m (图1)。 


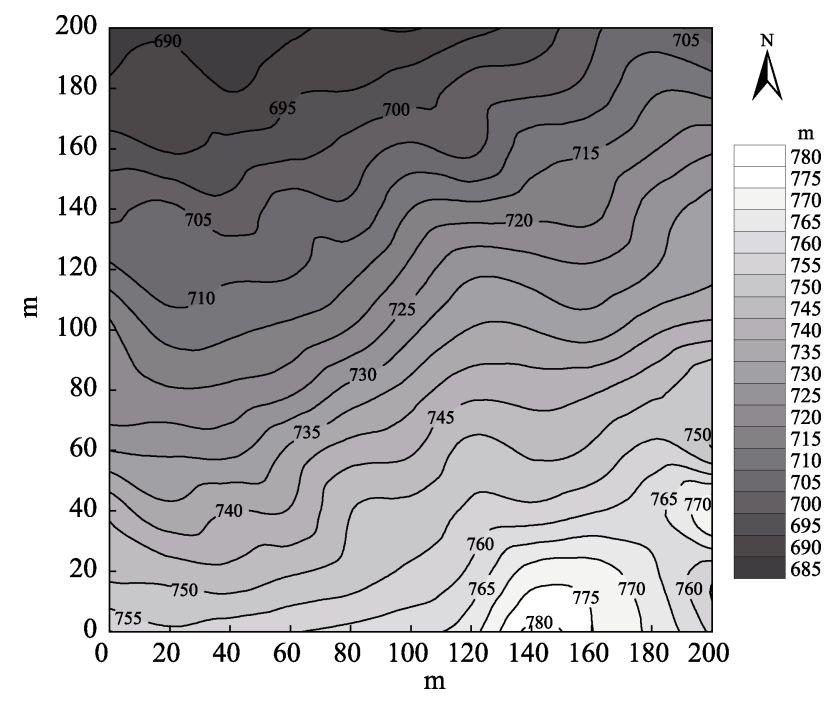

图1 辽东山区次生林固定监测样地的地形图

Fig. 1 Topography of the 4 ha secondary forest plot in montane region of eastern Liaoning Province

\subsection{2 幼苗样方设置与调查}

将每个 $20 \mathrm{~m} \times 20 \mathrm{~m}$ 样方划分成 16 个 $5 \mathrm{~m} \times 5 \mathrm{~m}$ 的小样方, 整个样地共计 1,600 个。在每个小样方内 对所有 $\mathrm{DBH}<1 \mathrm{~cm}$ 且高度不低于 $10 \mathrm{~cm}$ 的幼苗进行 定位调查, 记录幼苗的树种名、高度及坐标等, 并 挂牌标记, 以便进行永久监测。2014年8月完成第一 次调查, 以后每年7-8月间调查1次, 以便了解幼苗 的树种组成及其年际动态。到2016年8月已经完成 了3次调查。

\subsection{3 数据分析方法}

(1)幼苗密度:

幼苗密度 $=$ 样方内幼苗个体数 $/$ 样方面积 $\left(25 \mathrm{~m}^{2}\right)$

幼苗密度变异系数 $(C V)=$ 幼苗密度标准偏差 $(S D) /$ 幼苗密度均值 $($ Mean $) \times 100 \%$

$(2)$ 幼苗死亡率 $(m)$ 与新增率 $(r)$ (Condit et al, 1999):

$$
\begin{aligned}
& m=\left(N_{0}-S_{\mathrm{t}}\right) / N_{0} \\
& r=\left(\ln N_{\mathrm{t}}-\ln S_{\mathrm{t}}\right) / T
\end{aligned}
$$

式中, $N_{0}$ 和 $N_{\mathrm{t}}$ 分别为样地中第1次和第2次调查幼苗 个体数, $S_{\mathrm{t}}$ 为第 2 次调查时仍存活的个体数, $T$ 为两次 调查的时间间隔。

(3)幼苗重要值:

重要值 $=($ 相对多度 + 相对频度 $) / 2$

相对多度 $=($ 某种幼苗的多度/所有幼苗多度 和) $\times 100 \%$

相对频度 $=$ (某种幼苗的频度/所有幼苗频度
和) $\times 100 \%$

(4)非参数的多元方差分析：这是一种利用置 换方法来检验多元方差分析的非参数程序，也称为 基于置换的多元方差分析 (permutation based MANOVA, perMANOVA), 可用于在距离测量的基 础上进行多变量和单变量方差分析 (Anderson, 2005)。本研究用perMANOVA检验调查期间乔木幼 苗的组成和分布是否存在差异, plots $\times$ species为主 矩阵，用Sorensen (Bray-Curtis)做距离测量，以年份 为分组变量, perMANOVA的结果用传统方差分析 表的形式输出。

(5)配对 $t$ 检验：又称非独立两样本均数 $t$ 检验, 适用于样本量相同的配对设计资料均数的比较, 目 的是检验两个相关样本均数所代表的未知总体均 数是否存在差别。本研究中配对 $t$ 检验用于检验调查 期间任意两年间单个样方内幼苗的树种数量是否 存在差异。

采 用 Microsoft Excel 2013 和 R 3.3.2 (http://www.r-project)进行数据统计和分析, R 3.3.2 和Origin 9.0进行作图。

\section{结果}

\section{1 乔木幼苗物种组成与数量特征}

2014-2016年3次调查中共记录到22种乔木幼 苗，隶属12科14属(表1)。树种最多的科为槭树科(6 种)。主要树种幼苗为花曲柳(Fraxinus rhynchophylla)、色木槭、胡桃楸、水曲柳、暴马丁香(Syringa amurensis)、假色槭(Acer pseudo-sieboldianum)和山 杨(Populus davidiana)。调查期间，优势树种幼苗组 成在年际间没有发生变化，由于有的树种幼苗在某 一调查年内大量出现，因此各个树种的幼苗数量在 年际间稍有波动, 但花曲柳和色木槭始终具有明显 的优势地位，重要值均在前两位。

不同树种幼苗数量差异较大(表2): 花曲柳、色 木槭、胡桃楸幼苗数量之和占所有树种幼苗总数的 $68.6 \%$; 幼苗数量少于 100 的树种有 6 种，重要值总 和仅占 $2.02 \%$ 。幼苗频度差异较大，胡桃楸、色木槭 和花曲柳等分布较为广泛, 其他树种幼苗相对频度 较低, 变化范围为0.07-7.13\% (表2)。花曲柳、色木 槭和胡桃楸密度较大, 其他幼苗密度均较低, 且不 同树种幼苗密度在空间上的变异较大(表2)。

perMANOVA的结果显示，2014-2016年乔木幼 
苗的数量组成和分布存在极显著差异 $(F=4,016.3$, $P=0.001)($ 表3)。从 3 年乔木幼苗的数量组成和分布 的两两比较来看, 3 年间乔木幼苗的数量组成和分 布均存在极显著差异 $(P=0.001)$ (表3)。

\section{2 新增幼苗数量与组成}

2014-2016年间，共记录到20种5,598株新增乔 木幼苗。稠李(Prunus padus)和千金榆(Carpinus cordata)新增幼苗仅在2015年被监测到，花曲柳、色 木槭、胡桃楸等 18 个树种均出现新增幼苗，其中花 曲柳新增数量最多, 其次为胡桃楸和色木槭, 新增 数量均超过 500 株(表1)。

2015年新增幼苗3,888株(表1)，占新增幼苗总 数的 $69.45 \%$ 。调查时, 在 678 个样方内发现了新增幼 苗，单个样方内新增乔木幼苗种类最多为 7 种，出

表2 2014年幼苗组成与数量特征

Table 2 Species composition and quantitative characteristics of tree seedlings in 2014

\begin{tabular}{|c|c|c|c|c|c|c|}
\hline $\begin{array}{l}\text { 树种 } \\
\text { Species }\end{array}$ & $\begin{array}{l}\text { 幼苗数量 } \\
\text { No. of } \\
\text { seedlings }\end{array}$ & $\begin{array}{l}\text { 幼苗密度 } \\
\text { Seedling density } \\
\text { (mean } \pm S E \text {, } \\
n=1,600 \text { ) }\end{array}$ & $\begin{array}{l}\text { 幼苗密度变异系数 } \\
C V \text { of seedling } \\
\text { density (\%) }\end{array}$ & $\begin{array}{l}\text { 相对多度 } \\
\text { Relative } \\
\text { abundance }\end{array}$ & $\begin{array}{l}\text { 相对频度 } \\
\text { Relative } \\
\text { frequency }\end{array}$ & $\begin{array}{l}\text { 重要值 } \\
\text { Importance } \\
\text { value }\end{array}$ \\
\hline 花曲柳 Fraxinus rhynchophylla & 5,189 & $3.685 \pm 0.347$ & 376.97 & 32.93 & 10.81 & 21.87 \\
\hline 色木槭 Acer mono & 3,910 & $2.777 \pm 0.146$ & 209.71 & 24.81 & 17.13 & 20.97 \\
\hline 胡桃楸 Juglans mandshurica & 1,712 & $1.216 \pm 0.040$ & 131.52 & 10.86 & 19.53 & 15.20 \\
\hline 暴马丁香 Syringa amurensis & 827 & $0.587 \pm 0.042$ & 288.83 & 5.25 & 7.13 & 6.19 \\
\hline 假色槭 Acer pseudo-sieboldianum & 742 & $0.527 \pm 0.044$ & 336.29 & 4.71 & 5.53 & 5.12 \\
\hline 水曲柳 Fraxinus mandshruica & 622 & $0.442 \pm 0.042$ & 379.44 & 3.95 & 5.42 & 4.69 \\
\hline 山杨 Populus davidiana & 614 & $0.436 \pm 0.046$ & 425.41 & 3.90 & 3.17 & 3.54 \\
\hline 灯台树 Bothrocaryum controversum & 379 & $0.269 \pm 0.023$ & 348.90 & 2.40 & 4.58 & 3.49 \\
\hline 裂叶榆 Ulmus laciniata & 291 & $0.207 \pm 0.015$ & 283.45 & 1.85 & 4.93 & 3.39 \\
\hline 蒙古栎 Quercus mongolica & 240 & $0.170 \pm 0.016$ & 386.00 & 1.52 & 3.05 & 2.29 \\
\hline 青楷棫 Acer tegmentosum & 208 & $0.148 \pm 0.014$ & 379.95 & 1.32 & 3.01 & 2.17 \\
\hline 小楷槭 Acer komarovii & 178 & $0.126 \pm 0.012$ & 383.95 & 1.13 & 2.82 & 1.98 \\
\hline 怀槐 Maackia amurensis & 180 & $0.128 \pm 0.012$ & 378.25 & 1.14 & 2.71 & 1.93 \\
\hline 稠李 Prunus padus & 172 & $0.122 \pm 0.013$ & 440.27 & 1.09 & 2.55 & 1.82 \\
\hline 水榆花楸 Sorbus alnifolia & 143 & $0.102 \pm 0.010$ & 379.01 & 0.91 & 2.57 & 1.74 \\
\hline 千金榆 Carpinus cordata & 154 & $0.109 \pm 0.012$ & 434.08 & 0.98 & 2.34 & 1.66 \\
\hline 紫椴 Tilia amurensis & 86 & $0.061 \pm 0.007$ & 483.57 & 0.55 & 1.20 & 0.88 \\
\hline 花楷械 Acer ukurunduense & 41 & $0.029 \pm 0.008$ & $1,105.50$ & 0.26 & 0.58 & 0.42 \\
\hline 黄檗 Phellodendron amurense & 33 & $0.023 \pm 0.007$ & $1,215.70$ & 0.21 & 0.42 & 0.32 \\
\hline 春榆 Ulmus propinqua & 29 & $0.021 \pm 0.005$ & $1,022.49$ & 0.18 & 0.35 & 0.27 \\
\hline 黄榆 Ulmus macrocarpa & 7 & $0.005 \pm 0.002$ & $1,415.22$ & 0.04 & 0.12 & 0.08 \\
\hline 三花槭 Acer triflorum & 3 & $0.002 \pm 0.001$ & $2,164.87$ & 0.02 & 0.07 & 0.05 \\
\hline 总计 Total & 15,760 & & & 100.00 & 100.00 & 100.00 \\
\hline
\end{tabular}

表3 2014-2016年乔木幼苗的非参数多元方差分析

Table 3 The results of perMANOVA for tree seedlings during 2014-2016

\begin{tabular}{llllll}
\hline & 自由度 $\mathrm{df}$ & 平方和 SS & 均方和 MS & F & P \\
\hline 年份 Year & 2 & 343.18 & 171.591 & $4,016.3$ & $0.001^{* * *}$ \\
残差 Residuals & 4,797 & 204.95 & 0.043 & & \\
总数 Total & 4,799 & 548.13 & & $2,674.386$ & 0.001 \\
\hline 2014 vs. 2015 & & & $5,036.132$ & 0.001 \\
2014 vs. 2016 & & & $7,513.394$ & 0.001 \\
2015 vs. 2016 & & & & & \\
\hline
\end{tabular}


现的样方有 1 个, 出现1-3种新增幼苗的样方数量最 多, 共有 608 个。

2016年新增幼苗1,710株, 占新增幼苗总数的 $30.55 \%$, 有 789 个样方调查到新增幼苗, 出现树种 最多(5种)的样方有 2 个, 出现1种新增幼苗的样方数 量最多, 共有661个。新增幼苗的数量组成和分布在 年际间存在极显著差异(表4) $(F=2,701.5, P=$ $0.001)$ : 除胡桃楸之外, 其他树种新增幼苗数量都 表现为 2014-2015 年间多于 2015-2016 年间， 2014-2015年间幼苗新增总数是2015-2016年间的 2.3倍, 其中花曲柳、色木槭、山杨等树种幼苗新增 数量较多，2014-2015年间花曲柳新增数量是 2015-2016年间新增数量的11倍。胡桃楸幼苗新增 数量则表现为2015-2016年间明显多于2014-2015 年间, 前者约为后者的22倍。随着调查的进行, 新 增幼苗数量整体呈现下降趋势。

\section{3 死亡幼苗数量与组成}

2014-2015年间, 除黄榆(Ulmus macrocarpa)和 三花槭(Acer triflorum)之外, 20 个树种死亡幼苗共计 3,735株, 胡桃楸和花曲柳的死亡数量最多, 占死亡 总数的 $64.87 \%$, 死亡率最高的树种是胡桃楸 $(75.4 \%)$ (表1)。2015-2016年间, 除黄榆和三花槭之外, 20个 树种死亡幼苗共计 2,015 株, 死亡数量最多依次是 花曲柳、山杨和色木槭, 共计 1,402 株, 占死亡总数 的 69.58\%, 其中山杨的死亡率最高 (38.8\%), 且 2014-2015年间各个树种幼苗的死亡率整体上高于 2015-2016年间(表1), 通过比较新增幼苗和已有幼 苗的死亡情况可以发现, 新增幼苗死亡率明显高于 已有幼苗死亡率。

\section{4 幼苗高度级和树种分布}

2014-2016年3次幼苗调查统计结果显示(图2A): 幼苗数量随着高度级的增加而逐渐减少, 连续 3 年 群落内乔木幼苗都主要集于 $0.1-0.6 \mathrm{~m}$ 高度级间, 分 别占幼苗总数的 $74.5 \% 、 71.1 \%$ 和 $69.9 \%$, 其他高度 级间幼苗数量相对较少, 都出现偏峰现象。在
0.1-0.2 m高度级内幼苗个体数量最多。随着调查时 间的推移, 各高度级范围内的幼苗数量差距缩小, 其中 $0.1-0.2 \mathrm{~m} 、 0.2-0.3 \mathrm{~m} 、 0.3-0.4 \mathrm{~m}$ 和 $0.4-0.5 \mathrm{~m}$ 高 度级范围内的幼苗数量差距明显缩小。处于单个样 方内的乔木幼苗的树种数也出现偏峰现象。

对3次调查中 1,600 个 $5 \mathrm{~m} \times 5 \mathrm{~m}$ 小样方内幼苗树 种数统计发现(图2B), 2014-2016年间任意两年间单 个样方内监测的幼苗的树种数量均存在显著差异 (配对 $t$ 检验: 2014 vs. 2015, $P<0.001 ; 2014$ vs. 2016, $P=0.003 ； 2015$ vs. 2016, $P<0.001)$ ：在2014年，没 有乔木幼苗出现的样方有192个, 1种乔木幼苗出现 的样方有 381 个，2-5种乔木幼苗出现的样方有 821 个(51.3\%)，12种乔木幼苗出现的样方有1个。2015 年，没有乔木幼苗出现的样方有 334 个，1种乔木幼 苗出现的样方有366个，2-5种乔木幼苗出现的样方 有716个(44.8\%), 13种乔木幼苗出现的样方有 1 个。 2016年，没有乔木幼苗出现的样方有189个，1种乔 木幼苗出现的样方 407 个, 2-5种乔木幼苗出现的样方 有 815 个(50.9\%), 13种乔木幼苗出现的样方有 1 个。

2014-2016年间死亡幼苗高度级分布情况分析 结果表明: 死亡幼苗主要集中在0.1-0.5 m高度级范 围内(图3A), 其他高度级范围内幼苗死亡数量相对 较少，随着幼苗高度的增加，死亡数量呈下降趋 势。从2015-2016年间新增和已有死亡幼苗的高度 级分布情况来看(图3B), 幼苗在低高度级间死亡数 量较多, 且死亡数量随高度级的增加而降低, 出现 明显的偏峰现象。

\section{5 幼苗的空间分布特征}

2014-2016年调查期间乔木幼苗出现的样方数 的比较结果表明(表1): 胡桃楸、色木槭和花曲柳出 现的样方数分别占总样方数的 $69.1 \% 、 53.2 \%$ 和 $34.6 \%$, 这与它们的幼苗数量较多是一致的, 而花 曲柳的数量明显多于色木槭和胡桃楸, 出现的样方 数明显少于后两者, 说明花曲柳幼苗的聚集程度更 高。胡桃楸在2015年出现的样方数明显少于2016年,

表4 2014-2016年新增乔木幼苗的非参数多元方差分析

Table 4 The results of perMANOVA for recruited tree seedlings during 2014-2016

\begin{tabular}{llllll} 
& 自由度 $\mathrm{df}$ & 平方和 SS & 均方和 MS & F & $P$ \\
\hline 年份 Year & 1 & 166.74 & 166.744 & $2,701.5$ & $0.001^{* * *}$ \\
残差 Residuals & 3,198 & 197.39 & 0.062 & & \\
总数 Total & 3,198 & 364.13 & & & \\
\hline
\end{tabular}



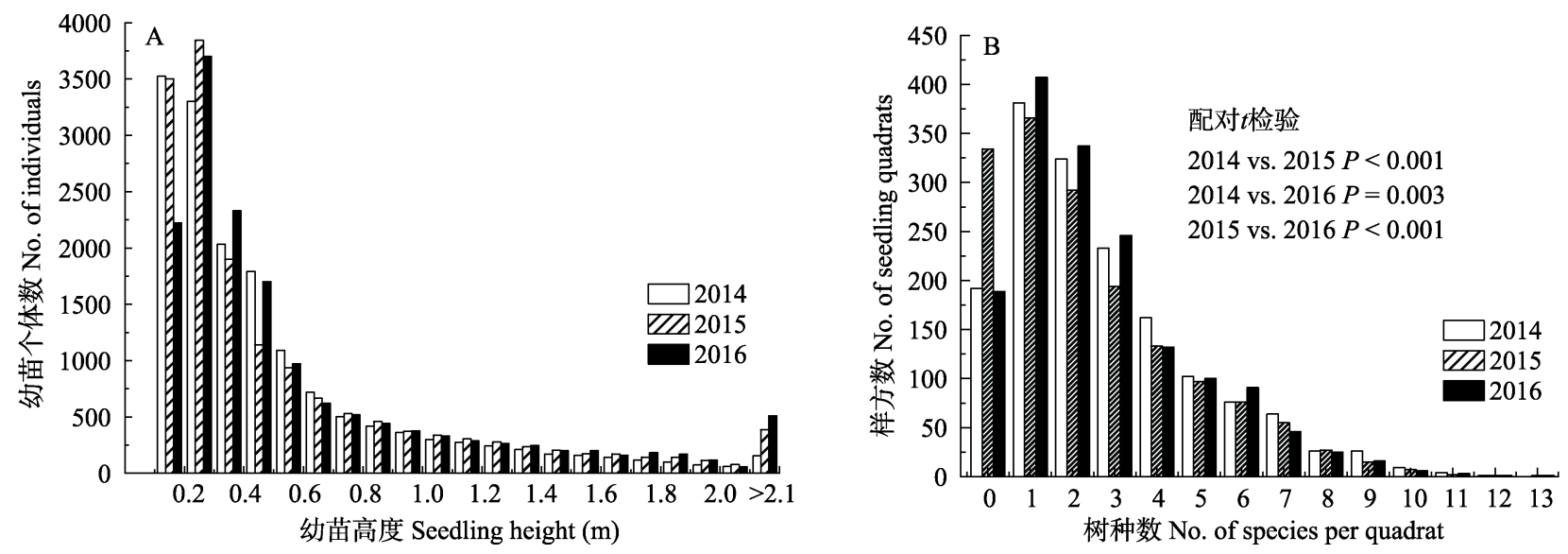

图2 2014-2016年间幼苗高度级分布和树种数出现的样方数

Fig. 2 Height distribution of seedlings and the number of quadrats occurred with number of species in 2014-2016
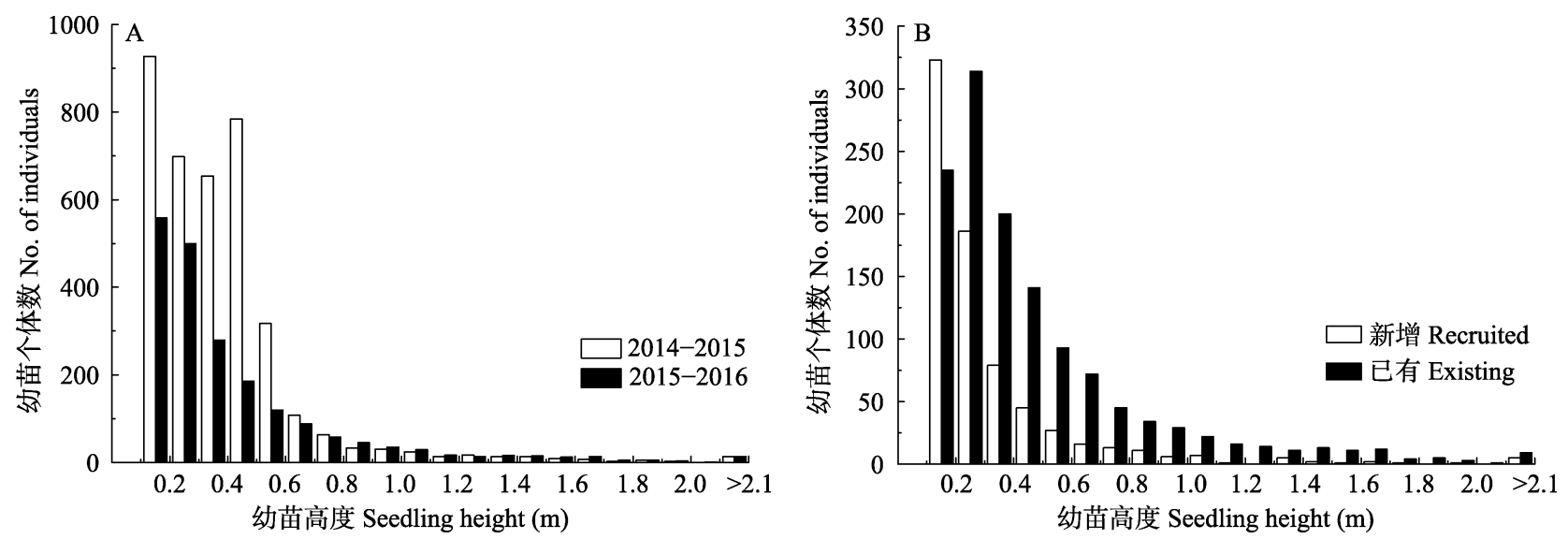

图3 2014-2016年间死亡幼苗高度级分布及2015-2016年间新增和已有死亡幼苗高度级分布

Fig. 3 Height distribution of dead seedlings in 2014-2016 and height distribution of dead recruited and existing seedlings in 2015-2016

出现明显的年际波动, 而色木棫和花曲柳幼苗出现 的样方数在2015年略高于2016年, 在 3 次调查期间 总体差异不大。调查期间, 仅6种乔木幼苗出现的样 方数量少于 100, 年际差异较小。

2014-2016年调查期间新增乔木幼苗出现的样 方数的比较结果表明(表1): 新增幼苗出现的样方 数量在不同树种和年际间出现较大差异, 除胡桃梑 外, 2014-2015年间新增幼苗出现的样方数多于 2015-2016年间，与年际间新增幼苗数量差异相一 致。调查期间，仅4种新增幼苗出现的样方数量大于 100, 2 个树种没有调查到新增幼苗。

\section{6 幼苗和大树空间分布的比较}

对样地内重要值排名前 10 位的幼苗和大树的 空间分布进行比较(附录1), 可以发现: 乔木幼苗在
空间分布上与大树具有一定的相似性, 绝大多数乔 木幼苗都表现出了集群分布的特点, 且幼苗的聚集 程度明显高于其母树的聚集程度。大树在整个样地 范围内均有分布, 乔木幼苗则主要分布在海拔 705-760 m间。大多数幼苗都集中在样地的东部, 样 地西部幼苗相对较少, 层次分明。尽管暴马丁香和 裂叶榆(Ulmus laciniata)大树的分布出现了一定的 空间异质性, 但大多数树种的大树也都集中在样地 的东部。除裂叶榆外，靠风力传播的树种的林下幼 苗都表现出了明显的集群分布, 其中花曲柳的聚集 程度最高, 而靠重力传播的胡桃楸幼苗分布较为随 机，且在样地内均有分布，但由于靠重力传播的胡 桃梑、灯台树和蒙古柇的种子也能被动物作为食物 而收集起来，使得它们的幼苗也表现出聚集分布的 
特点。在样地的西北角乔木幼苗数量最少, 即使是 大树明显表现出聚集分布的树种的林下幼苗也相 对较少, 如暴马丁香和裂叶榆。

\section{3 讨论}

\section{1 乔木幼苗的组成特点}

2014-2016年调查期间共监测到22种乔木幼苗, 均在该样地乔木的树种组成范围内 (白雪娇等, 2015)。调查结果表明: 辽东山区次生林乔木幼苗的 树种组成较为丰富, 但与热带雨林(李晓亮等, 2009) 及亚热带常绿阔叶林(丁晖等, 2016)相比存在明显 差距。群落内乔木树种的林下幼苗树种组成在调查 期间没有发生变化, 说明该林分更新良好, 但各个 样方间出现极大差异, 这与优势树种幼苗的大量发 生和死亡有关。在该次生林样地群落中多度值排序 前5位的乔木树种中有3种乔木树种的林下幼苗重 要值排在前5位(表2), 表明林下幼苗的优势树种组 成与样地内优势树种成分保持着一定的相似性, 与 前人的研究结果一致(李晓亮等, 2009; 张健等, 2009; 间琰等, 2016), 即优势树种的林下幼苗同样 保持着优势地位。

\section{2 幼苗高度级结构}

幼苗个体数量大，早期死亡率高(谭一波等, 2010), 随幼苗高度的增加, 幼苗数量逐渐减少(闵 琰等, 2016), 死亡率逐渐降低。调查期间0.1-0.5 m 高度级范围内幼苗数量差距变化明显, 一是由于幼 苗主要集中在0.1-0.6 m高度级内, 幼苗随着年龄的 增长而过渡到下一高度级, 二是由于幼苗死亡也主 要集中在0.1-0.5 m高度级范围内(图3A), 使得在这 一高度级范围内各高度级间幼苗数量有明显波动。 张国盛等(2006)通过对毛乌素沙地天然臭柏(Sabina vulgaris)居群有性更新幼苗动态研究发现幼苗死亡 率随着高度级的增加而逐渐下降, 这一点在本研究 中也得到了体现：从2015-2016年间新增和已有死 亡幼苗的高度级分布情况来看(图3B), 幼苗在低高 度级间死亡率较高, 且幼苗的死亡率随高度级的增 加而降低。

\section{3 幼苗年际动态的影响因素}

乔木幼苗的数量在不同树种和年际间表现出 较大的差异, 其中胡桃楸和花曲柳幼苗数量在年际 间的波动较为明显, 这与种子丰歉年现象密切相 关。随着调查时间的推移, 幼苗数量整体上呈现下
降的趋势, 可能是随着幼苗龄级的增长, 种内和种 间的竞争加剧所致。此外，繁殖体的生物学特性(如 种子休眠、重力传播等)也会限制幼苗的数量。由于 种子丰歉年现象使得调查期间新增幼苗数量在不 同树种和年际间也存在明显差异，2015年调查到的 新增幼苗远多于2016年(表1)。2014-2015年间新增 幼苗出现的样方数与2015-2016年间出现的样方数 有显著差异(表1), 这种差异与年际间新增幼苗数量 的差异是一致的。对比2015-2016年间新增幼苗和 已有幼苗死亡情况，我们发现新增幼苗死亡率明显 高于已有幼苗(表1), 这与研究区冬季寒冷漫长密切 相关, 幼苗期是生长最脆弱的时期, 新增幼苗在经 历第一个生长季和冬季后的这段时期大量死亡 (Maher \& Germino, 2006; Simões \& Marques, 2010; Chang-Yang et al, 2013)。但幼苗死亡是十分复杂的 生态学过程, 往往受到很多因素的影响, 如种子的 大小和成熟程度。相关研究表明大型种子萌发的幼 苗比小型种子的幼苗更能对抗来自外界环境的胁 迫(Khurana \& Singh，2000), 大型种子和成熟程度 更高的种子储存着丰富的营养物质，可用于幼苗在 结构上的改变以适应外界环境。相对于其他树种, 山杨种子较小。因此, 除胡桃楸外, 山杨的已有和 新增幼苗的死亡率均高于其他树种。

千金榆是构成该样地群落的主要树种, 多度值 排在第5位(白雪娇等, 2015), 但其林下幼苗数量相 对较少, 且千金榆大树平均胸径为5.37 cm, 原因可 能是千金榆大树普遍没有达到结实的年龄。花曲柳 幼苗数量在3次调查中始终排在第一位，2015年调 查到的幼苗数量最多，其中新增幼苗占 $36.6 \%$, 但 花曲柳大树仅有230株(白雪娇等, 2015), 这可能与 树种的生活史对策有关。花曲柳属于 $r$ 对策型树种, 林下幼苗大量发生的同时，幼苗也大量死亡(表1), 因此, 种子和新增幼苗数量并不能限制花曲柳种群 更新, 环境条件或其他生物学因素引起幼苗的大量 死亡也许更为重要(张健等, 2009)。曾雪琴等(2008) 研究表明母树和光照是影响幼苗空间分布的主要 因素，从本研究中花曲柳幼苗和大树的空间分布图 (附录1)来看, 尽管花曲柳大树在整个样地都有分布, 但幼苗在样地内却表现为东多西少，原因可能是样 地东部花曲柳大树较多, 大多数树种的种子不能扩 散到距离母树较远的区域(Janzen, 1970; Connell, 1971), 也可能是样地东部地形有两条凸起, 光照时 
间相对于西部较长。胡桃楸幼苗数量在3次调查中 表现出明显的年际动态, 2014年调查到的幼苗数量 最多，在2014-2015年间大量死亡，在2015-2016年 间又大量发生，因此，2016年胡桃楸幼苗大多为新 增幼苗。胡桃楸属于 $k$ 对策型树种, 由胡桃楸幼苗和 大树的空间分布图(附录1)可以看出, 胡桃楸幼苗和 大树在样地内分布都较为均匀, 胡桃楸大量死亡可 能并不是由密度制约造成的, 环境条件或其他生物 学因素引起胡桃楸幼苗的大量死亡也许更为重要。 参照王永和陶大立(1998)对长白山主要树种耐旱性 的研究, 本研究对样地内主要树种耐旱性进行比较 发现, 相较于样地内的其他几个主要树种, 胡桃楸 的耐旱性最差, 我们认为胡桃楸幼苗大量死亡的原 因可能是样地内的水分条件满足不了其存活需求。 尽管隶属于槭树科的6种乔木幼苗都是以风力传播 种子为主, 但它们在幼苗数量、密度、新增和死亡 数量、新增幼苗更新率上都存在明显的差异。色木 槭和假色槭幼苗的数量相对较多, 年际间波动较小, 且在空间分布上存在相同的趋势: 即样地东部集群 分布。但色木槭幼苗在整个样地广泛分布, 假色槭 幼苗仅主要分布在样地的东部。假色槭幼苗不能在 样地西部大量出现的原因除了扩散限制外, 还可能 是该区域的生境条件不适合幼苗定居(Uriarte et al, 2005; 宗国等, 2018)。

综上所述, 辽东山区次生林乔木树种幼苗组 成、年际动态随调查年限、幼苗种类、幼苗空间分 布格局变化而变化。此外, 繁殖体的生物学特性(如 生活史对策、扩散方式、种子丰歉年现象等)对树种 幼苗组成、数量和年际动态也有极大的影响。很多 因素影响着幼苗的发生和存活, 包括光照、地形、 水分和土壤养分等环境因子(Collins \& Carson, 2004; Lin et al, 2014; Lu et al, 2015; Minami et al, 2015), 以及幼苗周围的邻近个体、动物、土壤微生物等生 物因子(Bai et al, 2012; Markl et al, 2012; Muhamed et al, 2013; Bagchi et al, 2014), 这些因子共同作用 于森林的更新。本研究仅分析了辽东山区次生林乔 木幼苗的组成特点及年际动态, 有关影响幼苗动态 和空间分布的关键因素还有待于进一步探索。

\section{参考文献}

Anderson MJ (2005) PERMANOVA: A FORTRAN Computer Program for Permutational Multivariate Analysis of Vari- ance. Department of Statistics, University of Auckland, Auckland.

Bagchi R, Gallery RE, Gripenberg S, Gurr SJ, Narayan L, Addis CE, Freckleton RP, Lewis OT (2014) Pathogens and insect herbivores drive rainforest plant diversity and composition. Nature, 506, 85-88.

Bai XJ, Queenborough SA, Wang XG, Zhang J, Li BH, Yuan ZQ, Xing DL, Lin F, Ye J, Hao ZQ (2012) Effects of local biotic neighbors and habitat heterogeneity on tree and shrub seedling survival in an old-growth temperate forest. Oecologia, 170, 755-765.

Bai XJ, Deng LP, Li LL, Niu SS, Han MN, Qin SJ, Zhou YB (2015) Distribution patterns of woody plants in a secondary forest in the montane region of eastern Liaoning Province, China. Acta Ecologica Sinica, 35, 98-105. (in Chinese with English abstract) [白雪娇, 邓莉萍, 李露露, 牛沙沙, 韩美 娜, 秦胜金, 周永斌 (2015) 辽东山区次生林木本植物空 间分布. 生态学报, 35, 98-105.]

Chang-Yang CH, Lu CL, Sun IF, Hsieh CF (2013) Long-term seedling dynamics of tree species in a subtropical rain forest, Taiwan. Taiwania, 58, 35-43.

Clark DA, Clark DB (1984) Spacing dynamics of a tropical rain forest tree: Evaluation of the Janzen-Connell model. The American Naturalist, 124, 769-788.

Collins RJ, Carson WP (2004) The effects of environment and life stage on Quercus abundance in the eastern deciduous forest, USA: Are sapling densities most responsive to environmental gradients? Forest Ecology and Management, 201, 241-258.

Condit R (1995) Research in large, long-term tropical forest plots. Trends in Ecology and Evolution, 10, 18-22.

Condit R, Ashton PS, Manokaran N, Lafrankie JV, Hubbell SP, Foster RB (1999) Dynamics of the forest communities at Pasoh and Barro Colorado: Comparing two 50-ha plots. Philosophical Transactions of the Royal Society of London, 354, 1739-1748.

Connell JH (1971) On the role of natural enemies in preventing competitive exclusion in some marine animals and in rain forest trees. Dynamics of Populations, 298, 298-312.

Connell JH, Green PT (2000) Seedling dynamics over thirty-two years in a tropical rain forest tree. Ecology, 81, 568-584.

Ding H, Fang YM, Yang XH, Yuan FY, He LH, Yao JF, Wu J, Chi B, Li Y, Chen SF (2016) Community characteristics of a subtropical evergreen broad-leaved forest in Huangshan, Anhui Province, East China. Biodiversity Science, 24, 875-887. (in Chinese with English abstract) [丁晖, 方炎明, 杨新虎，袁发银，何立恒，姚剑飞，吴俊，迟斌，李圭，陈 水飞 (2016) 黄山亚热带常绿阔叶林的群落特征. 生物 多样性, 24, 875-887.]

Fyllas NM, Politi PI, Galanidis A, Dimitrakopoulos PG, 
Arianoutsou M (2010) Simulating regeneration and vegetation dynamics in Mediterranean coniferous forests. Ecological Modelling, 221, 1494-1504.

Harms KE, Wright SJ, Calderón O, Hernández A, Herre EA (2000) Pervasive density-dependent recruitment enhances seedling diversity in a tropical forest. Nature, 404, 493-495.

Hu LL, Mao ZH, Zhu JJ, Liu ZG, Chen GH, Zhang LJ (2005) Classification and ordination of secondary forests in montane zone of eastern Liaoning Province. Acta Ecologica Sinica, 25, 2848-2854. (in Chinese with English abstract) [胡理乐, 毛志宏, 朱教君, 刘足根, 陈广华, 张立君 (2005) 辽东山区天然次生林的数量分类. 生态学报, 25, 2848-2854.]

Janzen DH (1970) Herbivores and the number of tree species in tropical forests. The American Naturalist, 104, 501-528.

Khurana E, Singh JS (2000) Influence of seed size on seedling growth of Albizia procera, under different soil water levels. Annals of Botany, 86, 1185-1192.

Kong XW, Hu WL, Zhang B, Wang YG (2002) Quantative classification of structural types of present secondary natural forests in eastern Liaoning. Journal of Liaoning Forestry Science and Technology, (3), 14-16. (in Chinese with English abstract) [孔祥文, 胡万良, 张冰, 王玉光 (2002) 辽 东山区现有次生林结构类型的数量分类. 辽宁林业科技, (3), 14-16.]

Li JQ, Song XY, Cao M (2016) Response of tree seedlings to altitudinal gradient and its seasonal variation in Ailao Mountain and Yulong Mountain, Yunnan Province, China. Chinese Journal of Applied Ecology, 27, 3403-3412. (in Chinese with English abstract) [李洁琼, 宋晓阳, 曹敏 (2016) 云南哀牢山和玉龙雪山森林树种幼苗对海拔梯度 的响应及其季节性差异. 应用生态学报, 27, 3403-3412.]

Li XF, Zhu JJ, Wang QL, Liu ZG, Hou CS, Yang HJ (2004) Snow/wind damage in natural secondary forests in Liaodong mountainous regions of Liaoning Province. Chinese Journal of Applied Ecology, 15, 941-946. (in Chinese with English abstract) [李秀芬, 朱教君, 王庆礼, 刘足根, 侯传生, 杨 焕君 (2004) 辽东山区天然次生林雪/风灾害成因及分析. 应用生态学报, 15, 941-946.]

Li XL, Wang H, Zheng Z, Lin LX, Deng XB, Cao M (2009) Composition, spatial distribution and survival during the dry season of tree seedlings in a tropical forest in Xishuangbanna, SW China. Chinese Journal of Plant Ecology, 33, 658-671. (in Chinese with English abstract) [李晓亮, 王洪, 郑征, 林露湘, 邓晓保, 曹敏 (2009) 西双版纳热带森林 树种幼苗的组成、空间分布和旱季存活. 植物生态学报, 33, 658-671.]

Lin F, Comita LS, Wang XG, Bai XJ, Yuan ZQ, Xing DL, Hao ZQ (2014) The contribution of understory light availability and biotic neighborhood to seedling survival in secondary versus old-growth temperate forest. Plant Ecology, 215,
795-807.

Lu J, Johnson DJ, Qiao X, Lu Z, Wang Q, Jiang M (2015) Density dependence and habitat preference shape seedling survival in a subtropical forest in central China. Journal of Plant Ecology, 8, 568-577.

Maher EL, Germino MJ (2006) Microsite differentiation among conifer species during seedling establishment at alpine treeline. Ecoscience, 13, 334-341.

Markl JS, Schleuning M, Forget PM, Jordano P, Lambert JE, Traveset A, Wright SJ, Böhning-Gaese K (2012) Meta-analysis of the effects of human disturbance on seed dispersal by animals. Conservation Biology, 26, 1072-1081.

Metz MR, Comita LS, Chen YY, Norden N, Condit R, Hubbell SP, Sun IF, Noor NSBM, Wright SJ (2008) Temporal and spatial variability in seedling dynamics: A cross-site comparison in four lowland tropical forests. Journal of Tropical Ecology, 24, 9-18.

Metz MR, Sousa WP, Valencia R (2010) Widespread density-dependent seedling mortality promotes species coexistence in a highly diverse Amazonian rain forest. Ecology, 91, 3675-3685.

Minami Y, Oba M, Kojima S (2015) Distribution pattern of coniferous seedlings after a partial harvest along a creek in a Canadian Pacific northwest forest. Journal of Forest Research, 20, 328-336.

Muhamed H, Maalouf JP, Michalet R (2013) Summer drought and canopy opening increase the strength of the oak seedlings-shrub spatial association. Annual of Forest Science, 70, 345-355.

Norden N, Chave J, Caubère A, Châtelet P, Ferroni N, Forget PM, Thébaud C (2007) Is temporal variation of seedling communities determined by environment or by seed arrival? A test in a neotropical forest. Journal of Ecology, 95, 507-516.

Peng SJ, Huang ZL, Peng SL, Ouyang XJ, Xu GL (2004) Factors influencing mortality of seed and seedling in plant nature regeneration process. Guihaia, 24, 113-121. (in Chinese with English abstract) [彭闪江, 黄忠良, 彭少麟, 欧阳学 军, 徐国良 (2004) 植物天然更新过程中种子和幼苗死 亡的影响因素. 广西植物, 24, 113-121.]

Shimono Y, Kudo G (2003) Intraspecific variations in seedling emergence and survival of Potentilla matsumurae (Rosaceae) between alpine fellfield and snowbed habitats. Annals of Botany, 91, 21-29.

Simões CG, Marques M (2010) The role of sprouts in the restoration of Atlantic rainforest in southern Brazil. Restoration Ecology, 15, 53-59.

Su Y, Jiao JY, Wang ZJ (2014) Characteristics of seedling survival in habitats of hill and gully slopes in hill-gully Loess Plateau region of northern Shaanxi. Chinese Journal of Plant Ecology, 38, 694-709. (in Chinese with English 
abstract) [苏嫄, 焦菊英, 王志杰 (2014) 陕北黄土丘陵沟 壑区坡沟立地环境下幼苗的存活特征. 植物生态学报, 38, 694-709.]

Swamy V, Terborgh J, Dexter KG, Best BD, Alvarez P, Cornejo F (2011) Are all seeds equal? Spatially explicit comparisons of seed fall and sapling recruitment in a tropical forest. Ecology Letters, 14, 195-201.

Tan YB, Zhan CA, Xiao ZX, Yang HD, Peng JH, Wu KS (2010) Population structure and dynamic characteristics of Machilus chinensis in Nan'ao Island, Guangdong Province. Chinese Journal of Ecology, 29, 1901-1906. (in Chinese with English abstract) [谭一波, 詹潮安, 肖泽金金, 杨海东, 彭剑华, 吴凯胜 (2010) 广东南澳岛中华楠种群结构及 动态特征. 生态学杂志, 29, 1901-1906.]

Uriarte M, Canham CJ, Zimmerman J, Brokaw N (2005) Seedling recruitment in a hurricane-driven tropical forest: Light limitation, density-dependence and the spatial distribution of parent trees. Journal of Ecology, 93, 291-304.

Wang M, Tao DL (1998) Drought-tolerance of main tree species in Changbai Mountain. Chinese Journal of Applied Ecology, 9, 7-10. (in Chinese with English abstract) [王沝, 陶大立 (1998) 长白山主要树种耐旱性的研究. 应用生 态学报, 9, 7-10.]

Wright SJ, Mullerlandau HC, Calderón O, Hernandéz A (2005) Annual and spatial variation in seedfall and seedling recruitment in a neotropical forest. Ecology, 86, 848-860.

Xi ZJ, Wang XJ, Song HJ, Zhao BQ, Hao J, Guo DG (2017) Short-term dynamics of the main trees seedings death and its relationship with topographic factors in a Pinus tabulaeformis forest in the Lingkong Mountain, Shanxi. Journal of Shanxi Agricultural Sciences, 45, 978-982. (in Chinese with English abstract) [席朝骏, 王晓军, 宋厚娟, 赵冰清, 郝 婧, 郭东罡 (2017) 山西灵空山油松林主要乔木幼苗短 期死亡动态及其与地形因子的关系. 山西农业科学, 45, 978-982.]

Xu ZB, Dai LM, Chen JQ, Wang Z, Dai HC, Li X (2001) Natural regeneration condition in Pinus koraiensis broad-leaved mixed forest. Acta Ecologica Sinica, 21, 1413-1420. (in Chinese with English abstract) [徐振邦, 代力民, 陈吉泉, 王战, 戴洪才, 李听 (2001) 长白山红松阔叶混交林森林
天然更新条件的研究. 生态学报, 21, 1413-1420.]

Yan Y, Zhang XN, Yao J, Zhang CY, Zhao XH (2016) Composition and temporal dynamics of tree seedlings at different successional stages of conifer and broad-leaved mixed forests in Jiaohe, Jilin Province, China. Chinese Journal of Plant Ecology, 40, 127-139. (in Chinese with English abstract) [问琰, 张新娜, 姚杰, 张春雨, 赵秀海 (2016) 吉 林蛟河不同演替阶段针阔混交林乔木幼苗数量组成及其 时间动态. 植物生态学报, 40, 127-139.]

Zeng XQ, Chen LZ, Tan FY, Huang JH, Xu HL, Lin GH (2008) Seedling emergence and dispersal pattern of the introduced Sonneratia caseolaris in Shenzhen Bay, China. Biodiversity Science, 16, 236-244. (in Chinese with English abstract) [曾雪琴, 陈鹭真, 谭凤仪, 黄建辉, 徐华林, 林 光辉 (2008) 深圳湾引种红树植物海桑的幼苗发生和扩 散格局的生态响应. 生物多样性, 16, 236-244.]

Zhang GS, Wang Z, Wang LH, Hao YL, Wen GS (2006) Regenerative seedlings dynamics of natural Sabina vulgaris community in $\mathrm{Mu}$ Us sandland. Scientia Silvae Sinicae, 42(5), 62-67. (in Chinese with English abstract)[张国盛, 王 哲, 王林和, 郝云龙, 温国胜 (2006) 毛乌素沙地天然臭 柏居群有性更新幼苗动态研究. 林业科学, 42(5), 62-67.]

Zhang J, Li BH, Bai XJ, Yuan ZQ, Wang XG, Ye J, Hao ZQ (2009) Composition and interannual dynamics of tree seedlings in broad-leaved Korean pine (Pinus koraiensis) mixed forest in Changbai Mountain. Biodiversity Science, 17, 385-396. (in Chinese with English abstract) [张健, 李步杭, 白雪娇, 原作强, 王绪高, 叶吉, 郝占庆 (2009) 长白山 阔叶红松林乔木树种幼苗组成及其年际动态. 生物多样 性, 17, 385-396.]

Zong G, Bai XJ, Zhang SY, Cai JQ (2018) Spatial pattern and interspecific spatial association of tree seedlings in a secondary forest in montane region of eastern Liaoning Province, China. Chinese Journal of Applied Ecology, 29, 18-24. (in Chinese with English abstract) [宗国, 白雪娇, 张淑媛, 蔡 军奇 (2018) 辽东山区次生林乔木幼苗分布格局与种间 空间关联性. 应用生态学报, 29, 18-24.]

(责任编委：郝占庆 责任编辑: 黄祥忠、周玉荣)

\section{附录 Supplementary Material}

附录1 样地内10个主要树种的幼苗和大树的空间分布

Appendix 1 Spatial distributions of seedlings and trees of 10 main tree species http://www.biodiversity-science.net/fileup/PDF/2018135-1.pdf 


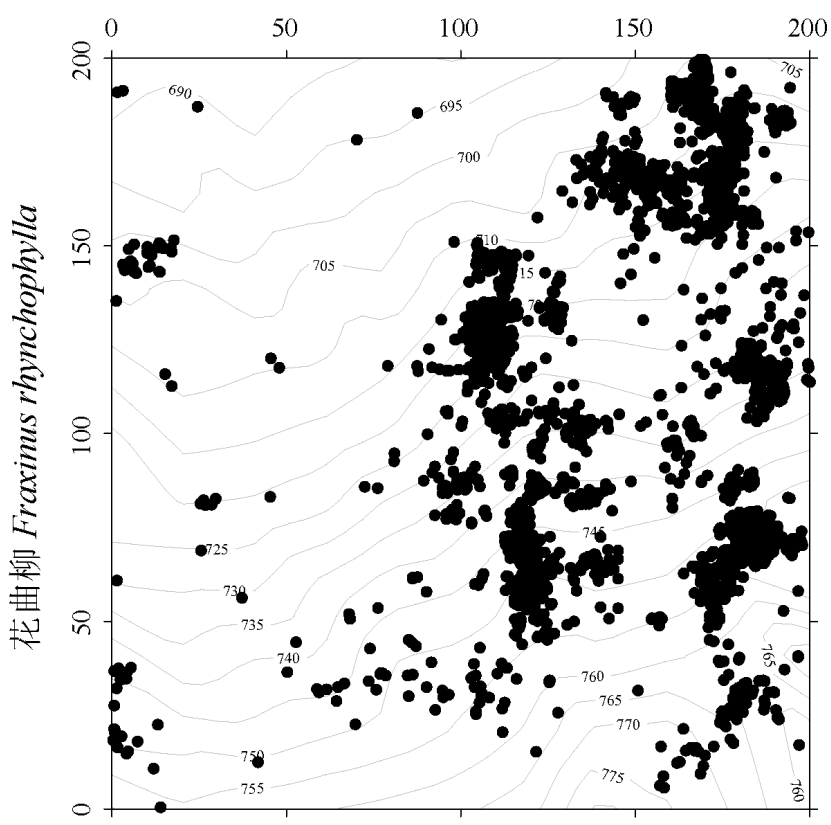

幼苗 Seedlings

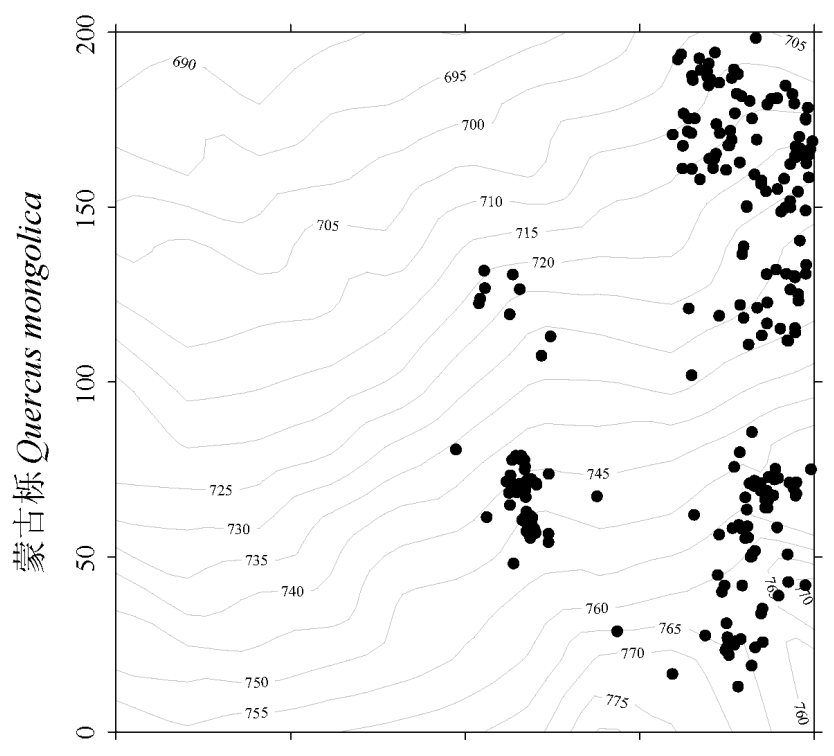

幼苗 Seedlings

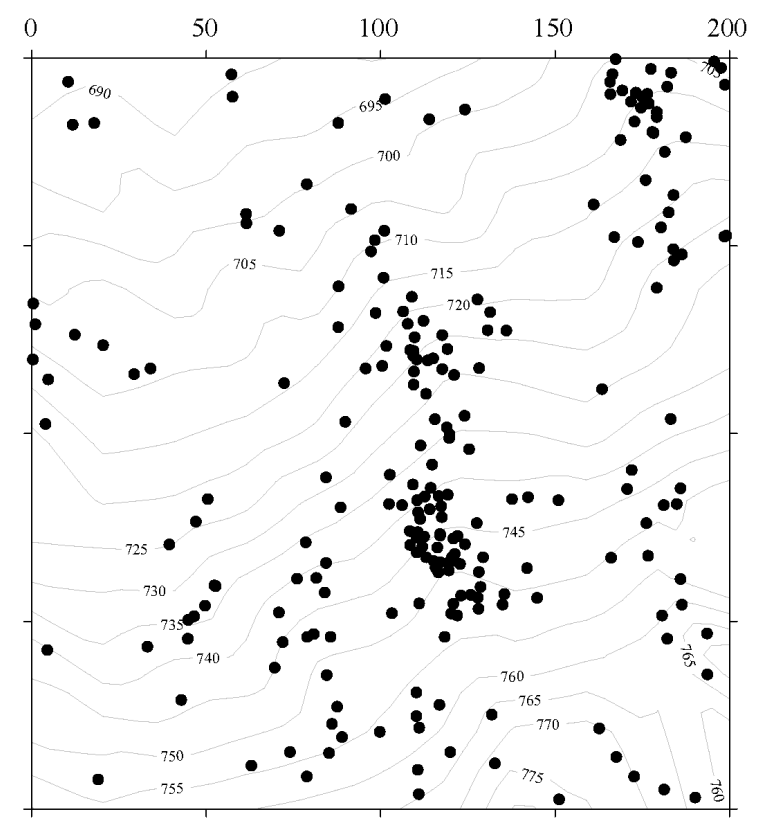

大树 Trees

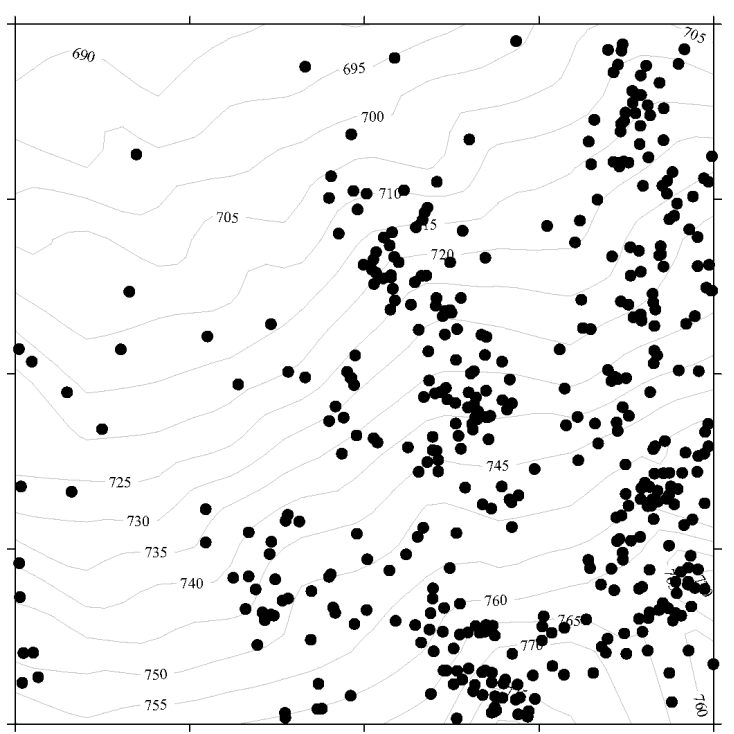

大树 Trees 


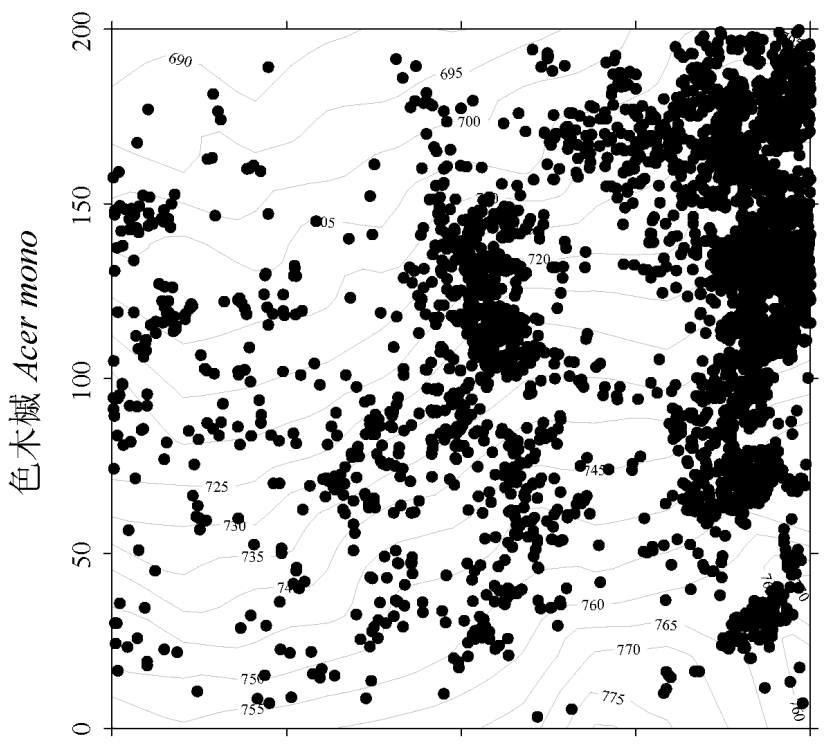

幼苗 Seedlings

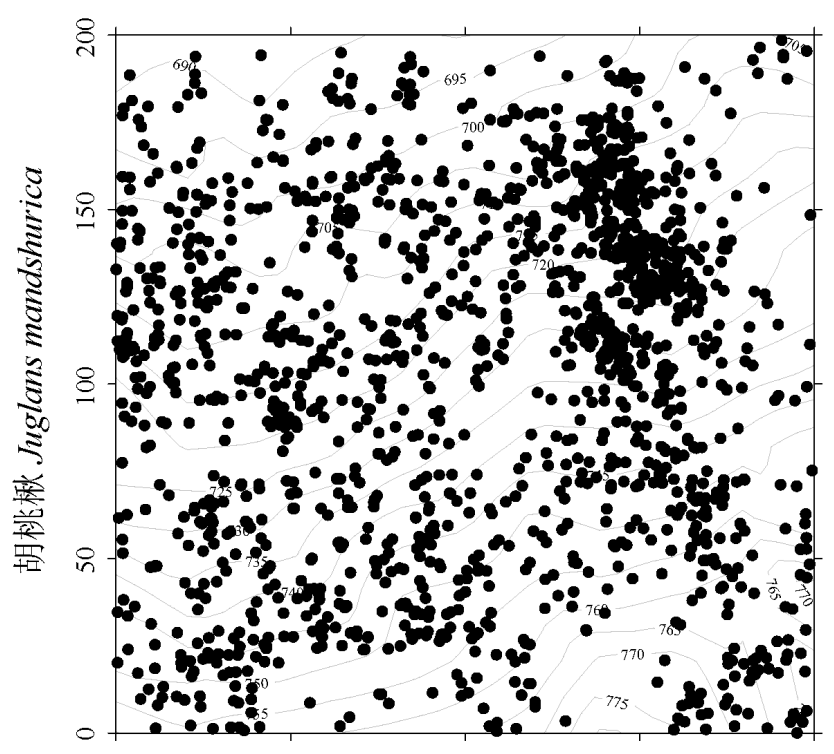

幼苗 Seedlings

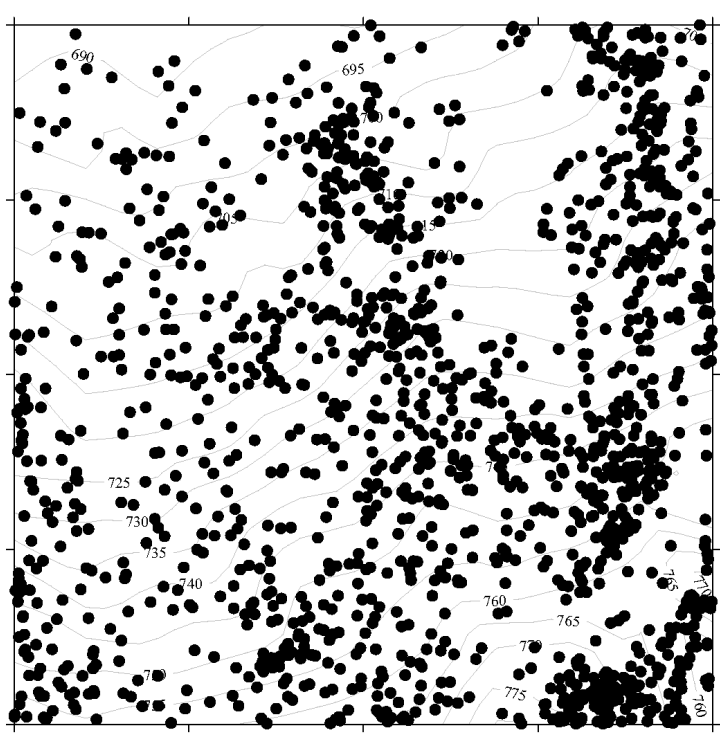

大树 Trees

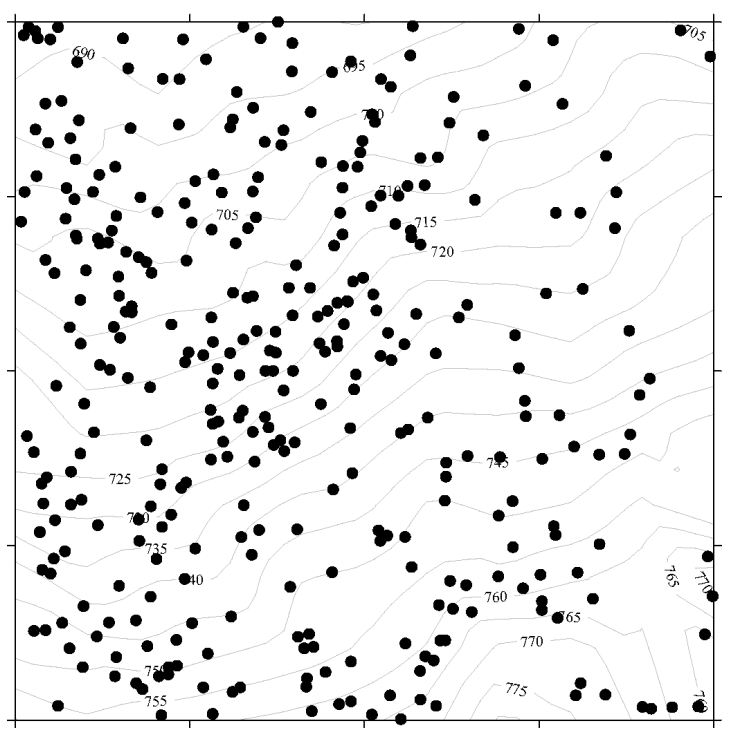

大树 Trees 


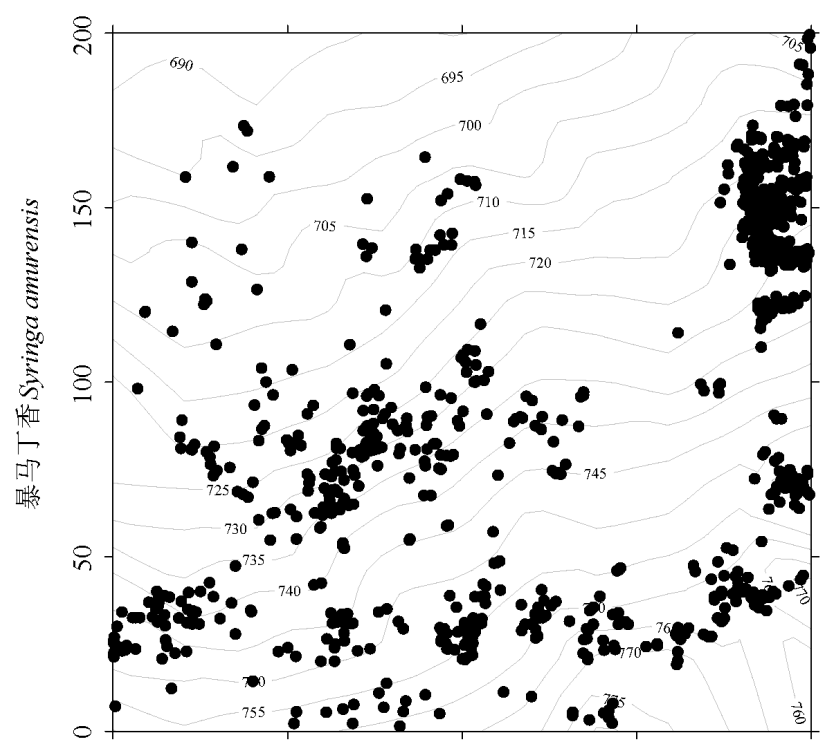

幼苗 Seedlings

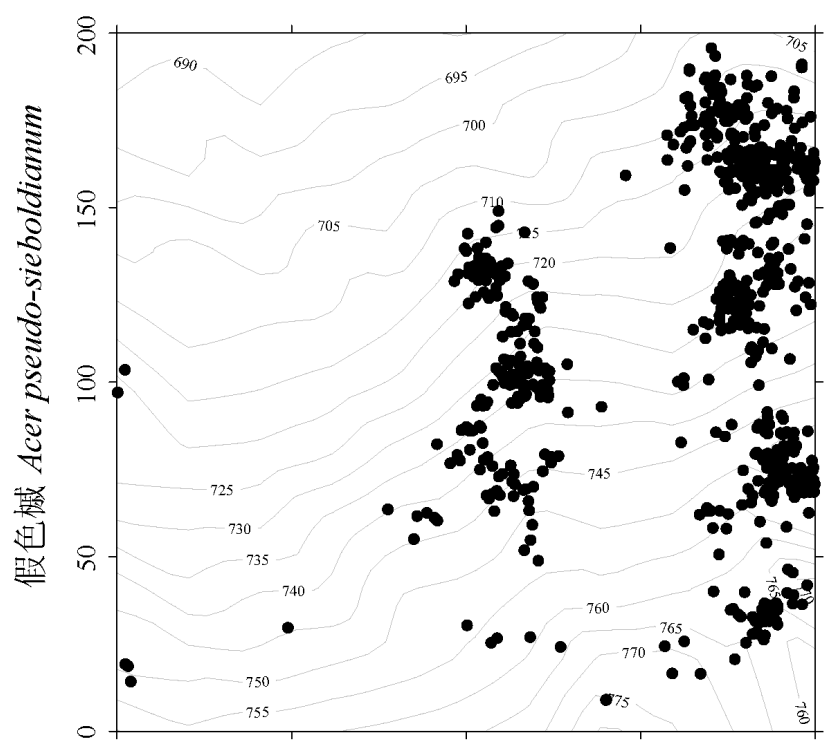

幼苗 Seedlings

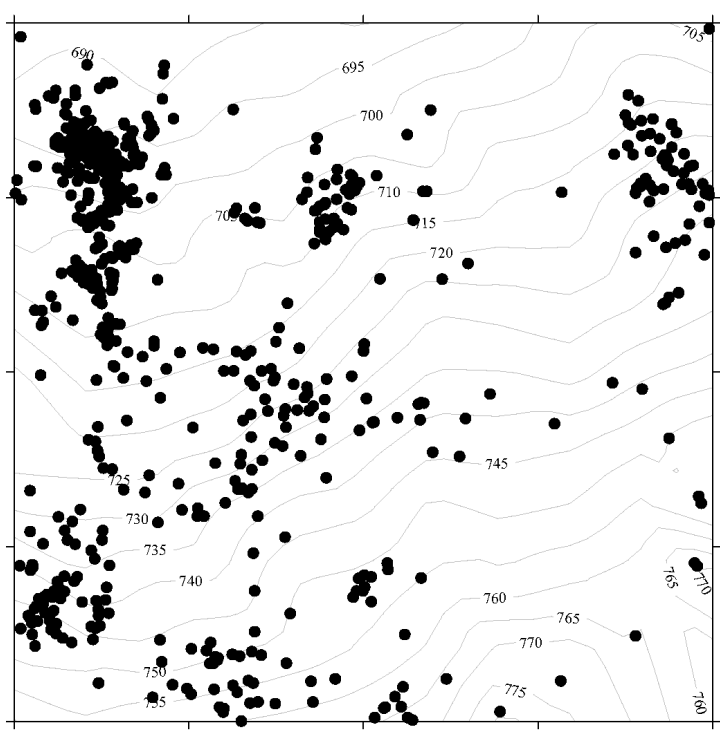

大树 Trees

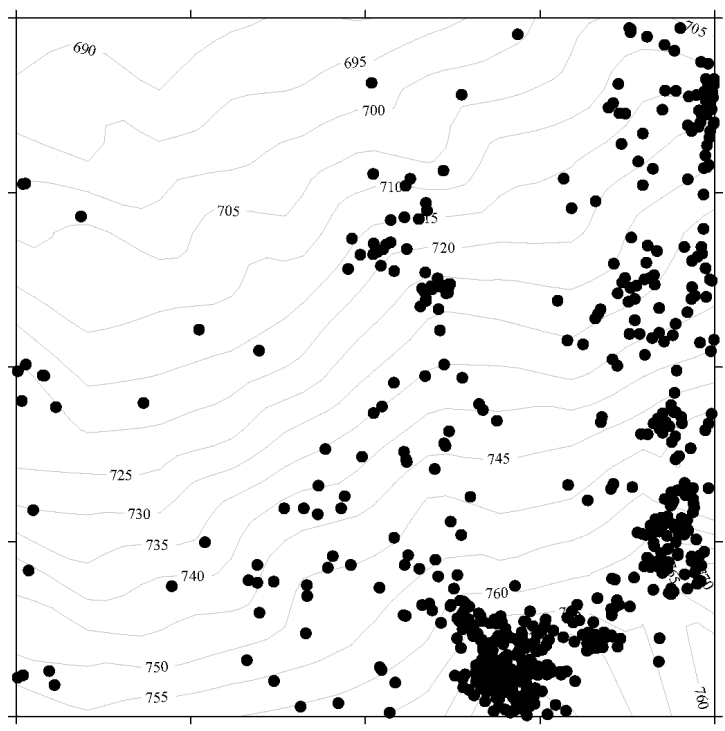

大树 Trees 


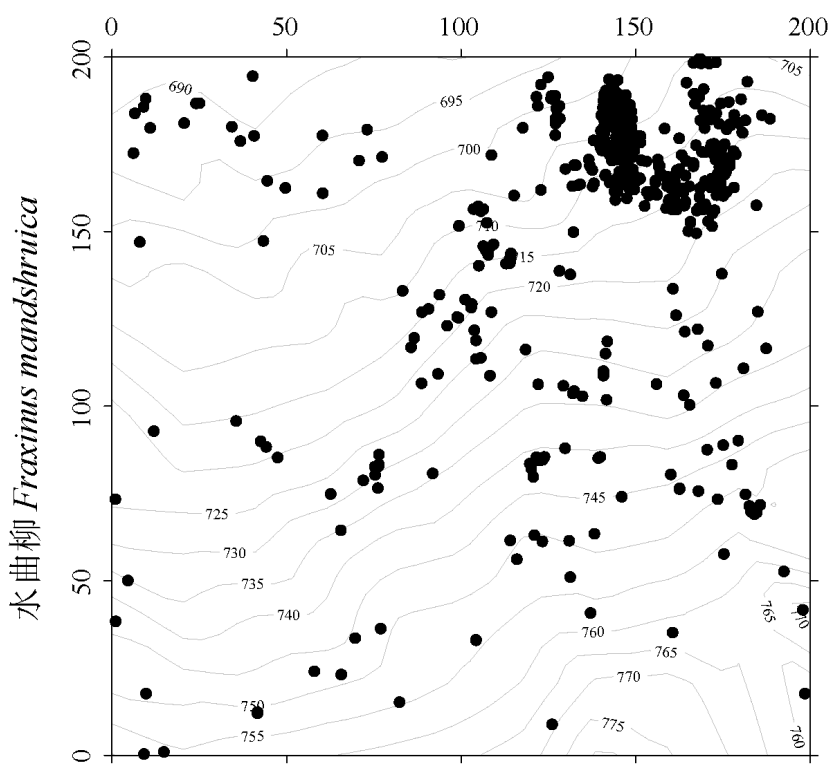

幼苗 Seedlings

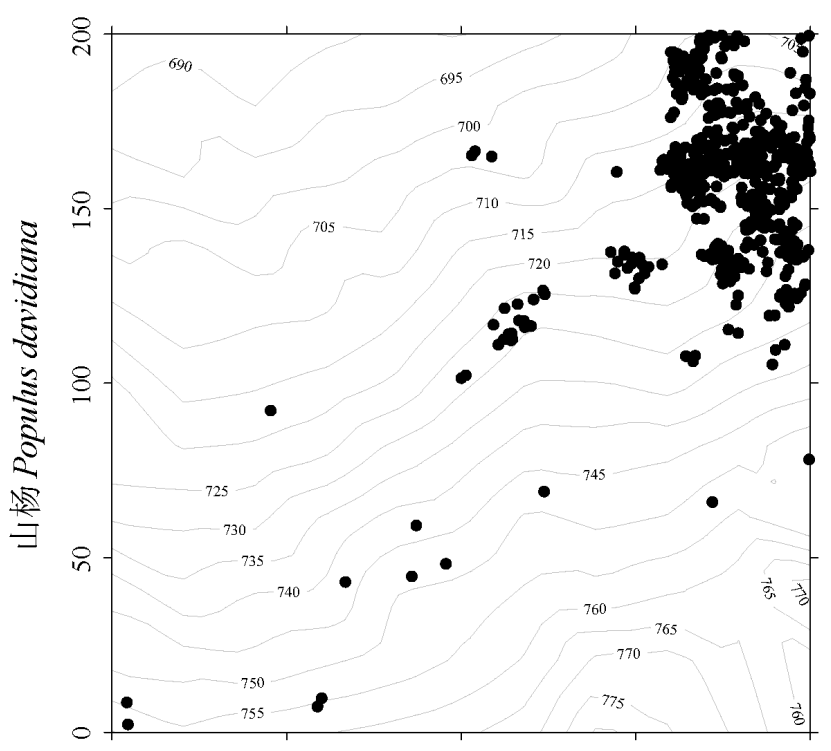

幼苗 Seedlings

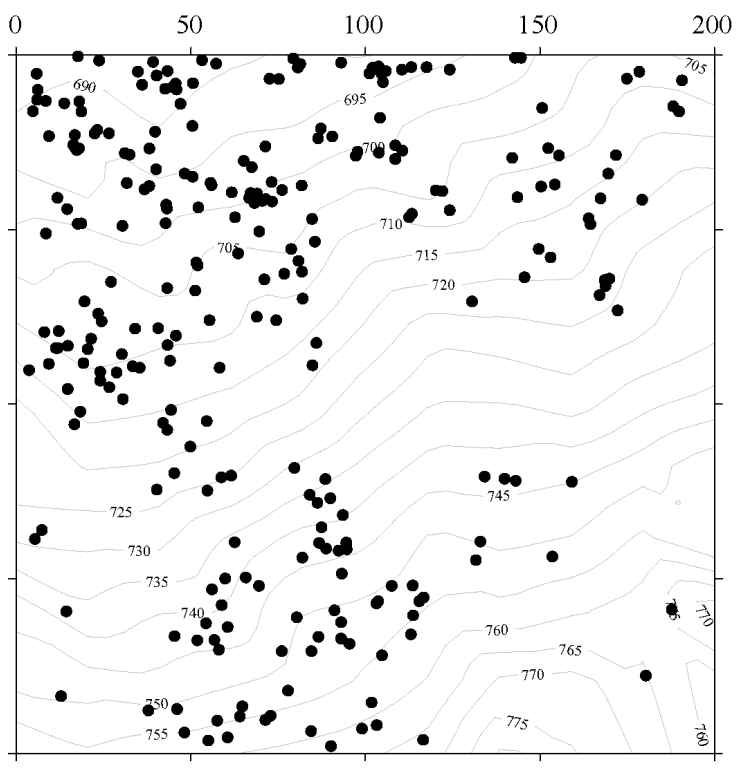

大树 Trees

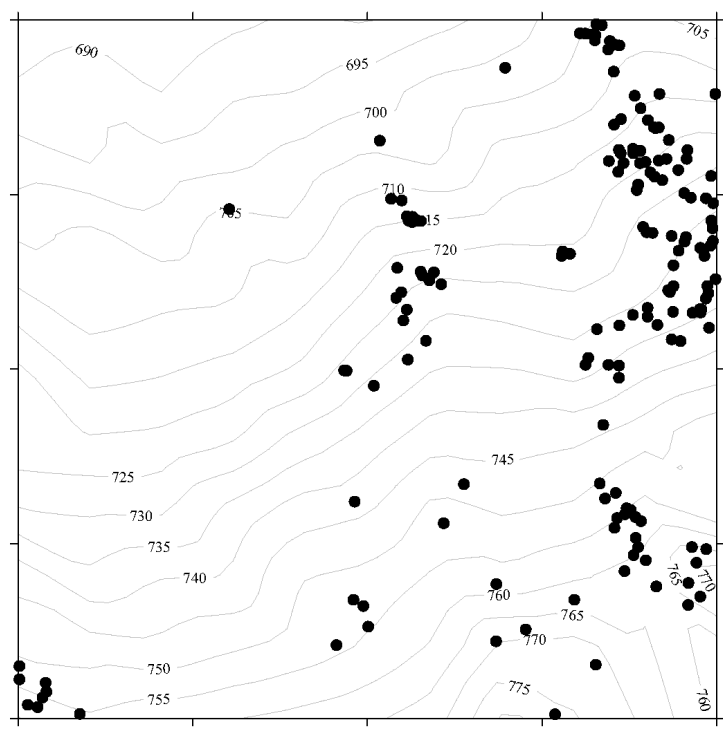

大树 Trees 


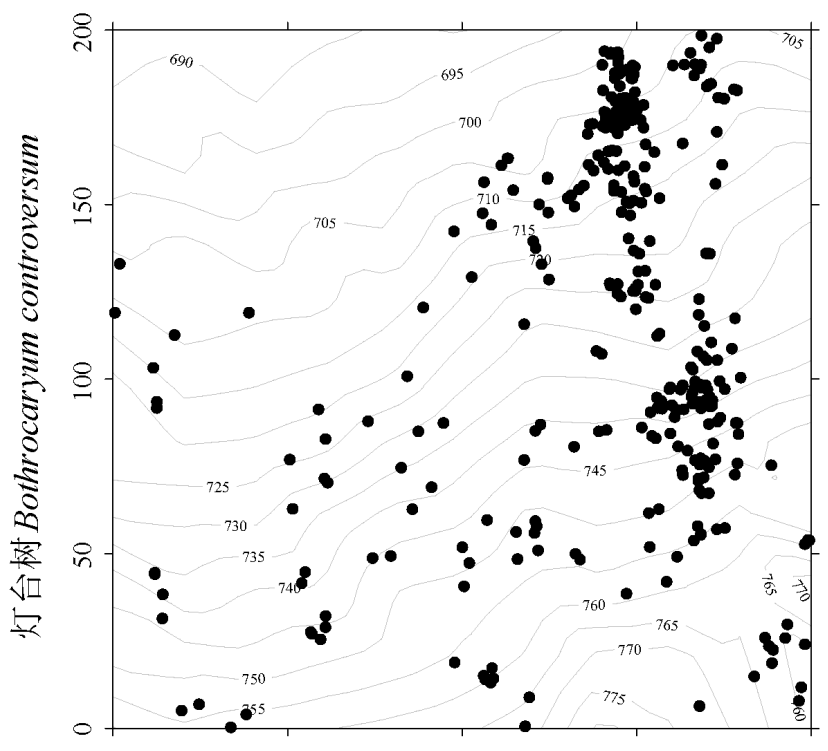

幼苗 Seedlings

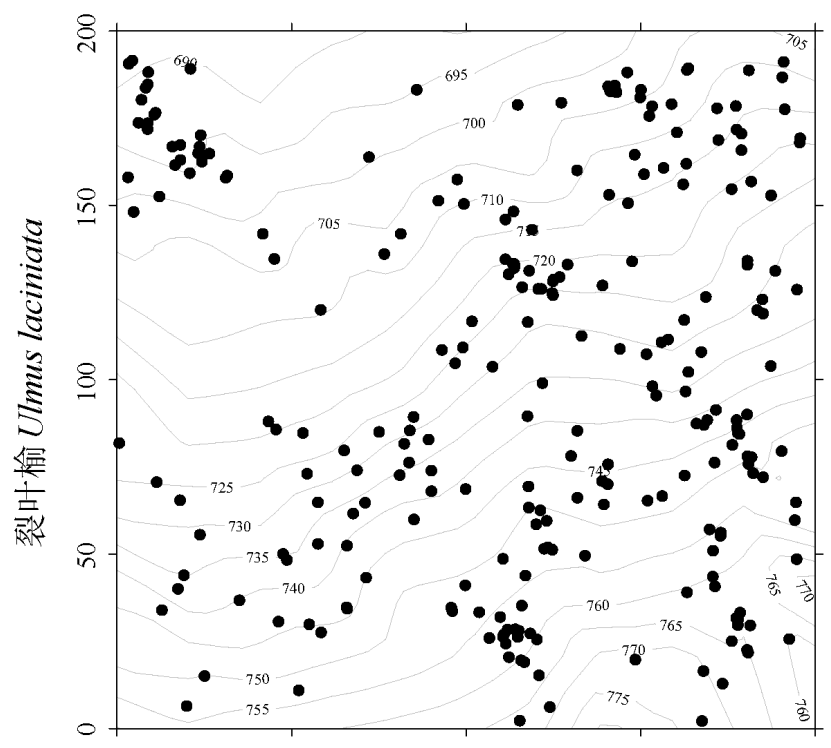

幼苗 Seedlings

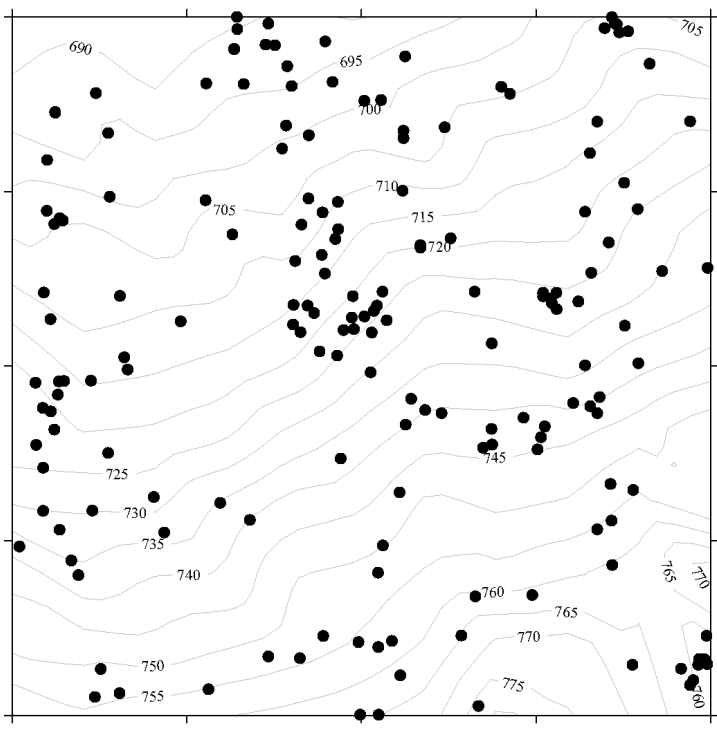

大树 Trees

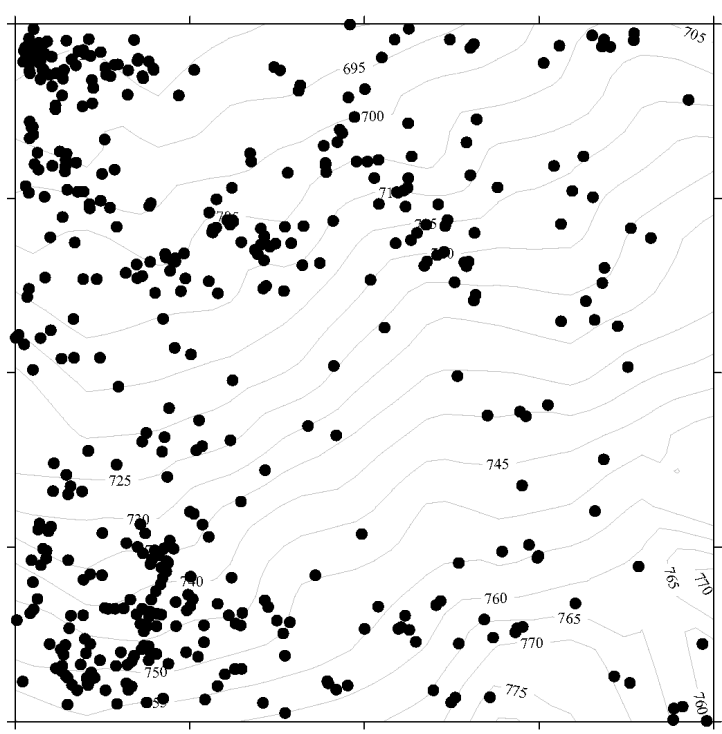

大树 Trees 